\begin{tabular}{|c|c|c|c|c|c|}
\hline MUNIBE Antropologia-Arkeologia & $\mathrm{n}^{0} 71$ & $73-89$ & DONOSTIA & 2020 & ISSN 1132-2217 • elSSN 2172-4555 \\
\hline
\end{tabular}

\title{
La secuencia prehistórica de la cueva de Abittaga (Amoroto, Bizkaia): evaluación de las excavaciones de J.M. Barandiarán (1964-1966)
}

\author{
The prehistoric sequence of Abittaga cave (Amoroto, Biscay): \\ review of J.M. Barandiarán excavations (1964-1966)
}

PALABRAS CLAVES: Magdaleniense Superior, Prehistoria Reciente, Industria ósea, Industria lítica, Cerámica, Macrofauna, Restos humanos GAKO-HITZAK: Goi Madeleine aldia, Historiaurre Hurbila, Hezur-industria, Industria litikoa, Zeramika. Makrofauna, Giza aztarnak. KEY WORDS: Late Magdalenian, Late Prehistory, Bone industry, Lithic industry, Pottery, Faunal remains, Human remains.

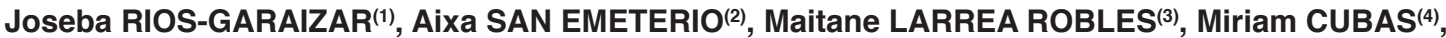 Andrea GARCÍA-SAGASTIBELZA( ${ }^{(5)}$, Diego GARATE MAIDAGAN( ${ }^{(6)}$, Rita PEYROTEO STJERNA(7), Carmen NÚÑEZ-LAHUERTA ${ }^{(8)}$, Asier GÓMEZ-OLIVENCIA ${ }^{(9)}$}

\section{RESUMEN}

El yacimiento de la cueva de Abittaga, excavado por J.M. Barandiarán entre 1964 y 1965, contiene una secuencia arqueológica con ocupaciones del Magdaleniense Superior y de la Prehistoria Reciente. Este yacimiento apenas ha participado en los debates de la prehistoria vasca de los últimos 40 años, fundamentalmente porque el yacimiento había sido estudiado de manera parcial y porque la información estratigráfica resultaba confusa. En este trabajo presentamos la revisión la colección arqueológica de Abittaga (industria lítica, ósea, cerámica, macrofauna y restos humanos). Se presentan además nuevas dataciones para las ocupaciones magdalenienses (nivel VII), y las de la Prehistoria Reciente (niveles I-III), y los resultados de la intervención arqueológica realizada en 2016. Estos resultados proporcionan una visión actualizada de un yacimiento usado con fines sepulcrales en la Edad del Bronce y como campamento ocasional, dentro de una amplia red de emplazamientos en la cuenca del Lea, durante el Magdaleniense Superior.

\section{LABURPENA}

J.M. Barandiaranek, 1964 eta 1965 artean, Goi Madeleine aldiko eta Historiarre Hurbileko okupazioak dituen Abittaga kobazuloko aztarnategiaren segida arkeologikoa induskatu zuen. Aztarnategi horrek oso parte-hartze txikia izan du euskal historiaurrearen inguruan azken 40 urteotan egin izan diren eztabaidetan; horretarako arrazoiak bi dira batez ere: aztarnategia modu partzialean aztertu zutelako eta informazio estratigrafikoa nahasia zelako. Lan honetan, Abittagako bilduma arkeologikoaren (industria litikoa, hezurrak, zeramikoa, makrofauna eta giza aztarnak) berrikusketa aurkezten dugu. Gainera, Madeleine aldiko okupazioetarako datazio berriak (VII. maila) eta Historiaurre Hurbilekoak (I-II mailak), eta 2016an egindako lan arkeologikoko emaitzak aurkezten dira. Emaitza hauek aztarnatergiaren ikuspegi eguneratua eskaintzen dute. Brontze Aroan kobazuloa hilobi gisa erabilia izan zen. Bestalde, Goi Madeleine aldian Lea ibaiaren arroan garai horrentan zegoen kokaleku sareko aldizkako kanpamentua bezala erabilia izan zen.

\footnotetext{
(1) Programa de Arqueología, Centro Nacional de Investigación sobre la Evolución Humana (CENIEH), Paseo Sierra de Atapuerca 3 · 09002 Burgos. joseba.rios@cenieh.es

(2) Programa de Arqueología, Centro Nacional de Investigación sobre la Evolución Humana (CENIEH), Paseo Sierra de Atapuerca $3 \cdot 09002$ Burgos. aixa.sanemeterio@cenieh.es

(3) maitane.larrea@gmail.com

(4) Departamento de Historia, Universidad de Oviedo. C/ Amparo Pedregal s/n 33011 Oviedo. Sociedad de Ciencias Aranzadi, Zorroagagaina 11, 20014 Donostia-San Sebastián.

(5) Dept. Geología, Facultad de Ciencia y Tecnología, Universidad del País Vasco-Euskal Herriko Unibertsitatea (UPV/EHU). Barrio Sarriena s/n, 48940 Leioa. UMR 5199 PACEA, Université de Bordeaux. Allée Geoffroy Saint Hilaire, Bâtiment B8. CS 50023. 33615-Pessac Cedex, France. (6) Instituto Internacional de Investigaciones Prehistóricas de Cantabria (IIIPC), Gobierno de Cantabria. Avda. Los Castros s/n., 39005 Santander, España.

(7) Human Evolution, Dep Organismal Biology, Uppsala University. Norbyv. 18C, 75236 Uppsala, Sweden. UNIARQ, Centro de Arqueologia, Universidade de Lisboa, Portugal.

(8) Departamento de Ciências da Terra, Faculdade de Ciências e Tecnologia, FCT, Universidade Nova de Lisboa, 2829-516 Caparica, Portugal Museu da Lourinhã, Rua João de Moura 95, 2530-158 Lourinhã, Portugal. Aragosaurus-IUCA, Departamento de Ciencias de la Tierra, Facultad de Ciencias, Universidad de Zaragoza, C/ Pedro Cerbuna, 12, 50009 Zaragoza.

(9) Dept. Geología, Facultad de Ciencia y Tecnología, Universidad del País Vasco-Euskal Herriko Unibertsitatea (UPV/EHU). Barrio Sarriena s/n, 48940 Leioa. Sociedad de Ciencias Aranzadi, Zorroagagaina 11, 20014 Donostia-San Sebastián. Centro UCM-ISCIII de Investigación sobre Evolución y Comportamiento Humanos, Avda. Monforte de Lemos 5 (Pabellón 14), 28029 Madrid.
} 


\begin{abstract}
The archaeological site of Abittaga cave, excavated by J.M. Barandiarán between 1964 and 1965, has yielded a stratigraphic sequence with Late Magdalenian and Recent Prehistory occupations. For several reasons, this site has barely contributed to the debates about the Basque Prehistory during the last 40 years, debates such as the subsistence strategies and cultural transformations of the last hunter gatherers in the region, or the use of caves by the first farmer communities. This can probably be explained not only by the absence of a complete comprehensive analysis of the site and the archaeological materials, but also because some of the information provided by J.M. Barandiarán about the site, specially about its stratigraphy, was rather confusing.

In this work we present the systematic revision of the archaeo-palaeontological collection, and we offer new data about the lithic tools, bone industry, pottery, and faunal and human remains. The analysis of the documentation of the site recorded by J.M. Barandiarán and J.M. Apellániz complemented with the results of the excavation made in 2016 at the site, suggest that the archaeological deposits excavated by J.M. Barandiarán probably correspond with deposits in primary position preserved only by the right wall of the entrance hall of the cave. The analysis of the pottery assemblage suggests different uses of the cave between the III and the I millennium cal BC. The presence of a single human individual buried in levels I-III, directly dated between 1895-1689 cal BC, indicates a funerary use of the cave during the Bronze Age. Levels IV-VI are really poor in archaeological materials and thus very difficult to interpret. Level VII presents the bulk of the archaeological material and it has been dated between 14321-14051 cal BP. In this level, the lithic assemblage is well preserved, with different refitting series. Almost all the lithic artifacts have been knapped using Flysch flint, but there are examples of flint varieties coming from more than 50 km of distance. We have recognized an in situ bladelet production obtained from carinated burins and small blocks, and the production of larger blades outside the cave, that were subsequently carried to Abittaga. The retouched toolkit is composed basically by burins, partially retouched blades and backed bladelets, with a remarkable absence of endscrapers. On the other hand, the bone industry is rich and varied, with bone points, single-row barbed harpoons, and rods. This lithic and bone industry is similar to other coeval sites in the same region such as Santa Catalina or Atxurra. The Late Magdalenian occupation of Abittaga cave is interpreted as a short-term occupation which was part of a wider settlement network that existed at that time in the Lea basin.
\end{abstract}

\section{INTRODUCCIÓN}

El yacimiento de la cueva de Abittaga (Amoroto, Bizkaia) fue excavado por J.M. Barandiarán entre 1964 y 1966. En 1964 realizó una cata de medio metro de profundidad en el vestíbulo de la cueva en la que recuperaron cerámicas prehistóricas. Posteriormente, entre 1965 y 1966 realizó dos campañas de excavación que fueron descritas en unas escuetas memorias (Barandiarán, 1969, 1971). Los materiales arqueológicos de las excavaciones de J.M. Barandiarán han sido posteriormente revisados por distintos autores que han abordado el estudio de los conjuntos paleolíticos (González Sainz, 1983; Fernández Eraso, 1985; Fernández Ibáñez, 1986; Larrea Robles, 2017) y postpaleolíticos (Apellániz, 1973; Arias, 1991). En 1970, J.M. Apellániz desarrolla una limitada intervención, ampliando la excavación de J.M. Barandiarán, pero sus resultados nunca fueron publicados. P. Castaños (1986) estudió para su tesis doctoral la fauna de toda la secuencia. Más recientemente en la cavidad se han documentado grafías rupestres, probablemente de cronología paleolítica (Garate et al., 2015), así como un depósito de armas del siglo XIX (Urrutia y Urrutia, 2005).

La adscripción cultural de los niveles superiores de la secuencia se realizó en función de los rasgos morfológicos y decorativos de la cerámica, así se adscribe el nivel III, "...en el que comienza la cerámica...", al Neolítico (Barandiarán, 1971: 306). Posteriormente, los niveles II y I se adscribieron a la Edad del Bronce y del Hierro respectivamente (Barandiarán, 1971: 306). La adscripción del nivel III al Neolítico se mantuvo en una revisión posterior (Arias, 1991) aunque fue considerada como dudosa, sosteniendo que "...las colecciones de los niveles III a V son demasiado pobres como para ser atribuidas a cualquier fase cronoestratigráfica..." (Arias, 1991: 58). Por otro lado, los niveles V-VI se atribuyen por J.M. Barandiarán al Epipaleolítico, no siendo clara la atribución del nivel IV. El nivel VII se asigna, según el sistema clásico de periodización, al Magdaleniense VI (Barandiarán, 1971). Posteriormente C. González Sainz concretó la pertenencia del nivel VII al Magdaleniense Superior final cantábrico basándose en sus industrias óseas y líticas, en cuanto a los niveles IV a VI observa en ellos una clara tradición paleolítica, más similares al Magdaleniense que a un Aziliense (González Sainz, 1983: 71).

A pesar de estos trabajos, las ocupaciones del final del Paleolítico Superior y de la Prehistoria Reciente de la cueva de Abittaga apenas han contribuido al conocimiento del Magdaleniense y de la Edad del Bronce en la región cantábrica. A este desinterés por el yacimiento han contribuido la confusa estratigrafía descrita por J.M. Barandiarán, la ausencia de dataciones directas y la falta de un estudio de conjunto de las evidencias arqueológicas, incluyendo la industria lítica, la ósea, la cerámica, así como de los restos humanos y de fauna recuperados en el yacimiento. En los últimos años, sin embargo, hay un renovado interés por el Paleolítico y la Prehistoria Reciente de la cuenca del río Lea, donde se enclava el yacimiento. La excavación en yacimientos emblemáticos como Santa Catalina, Lumentxa, Laminak II o Atxurra (Arribas, 1994; Berganza y Arribas, 1994, 2014a; Rios-Garaizar et al., 2019) y la localización de nuevos conjuntos de arte rupestre en Lumentxa, Atxurra, Armintxe, Goikolau u Ondaro (Garate et al., 2013, 2016-2017, 2020; González Sainz y López Quintana, 2017a, 2017b), han puesto de relieve la importancia de la ocupación humana prehistórica en esta comarca, especialmente durante el Magdaleniense, lo que la convierte en un lugar privilegiado para afrontar la investigación de cuestiones tan relevantes como las adaptaciones humanas a las condiciones ambientales del Tardiglacial, el uso del espacio (hábitats, santuarios, etc.), las tensiones entre la creciente regionalización y 


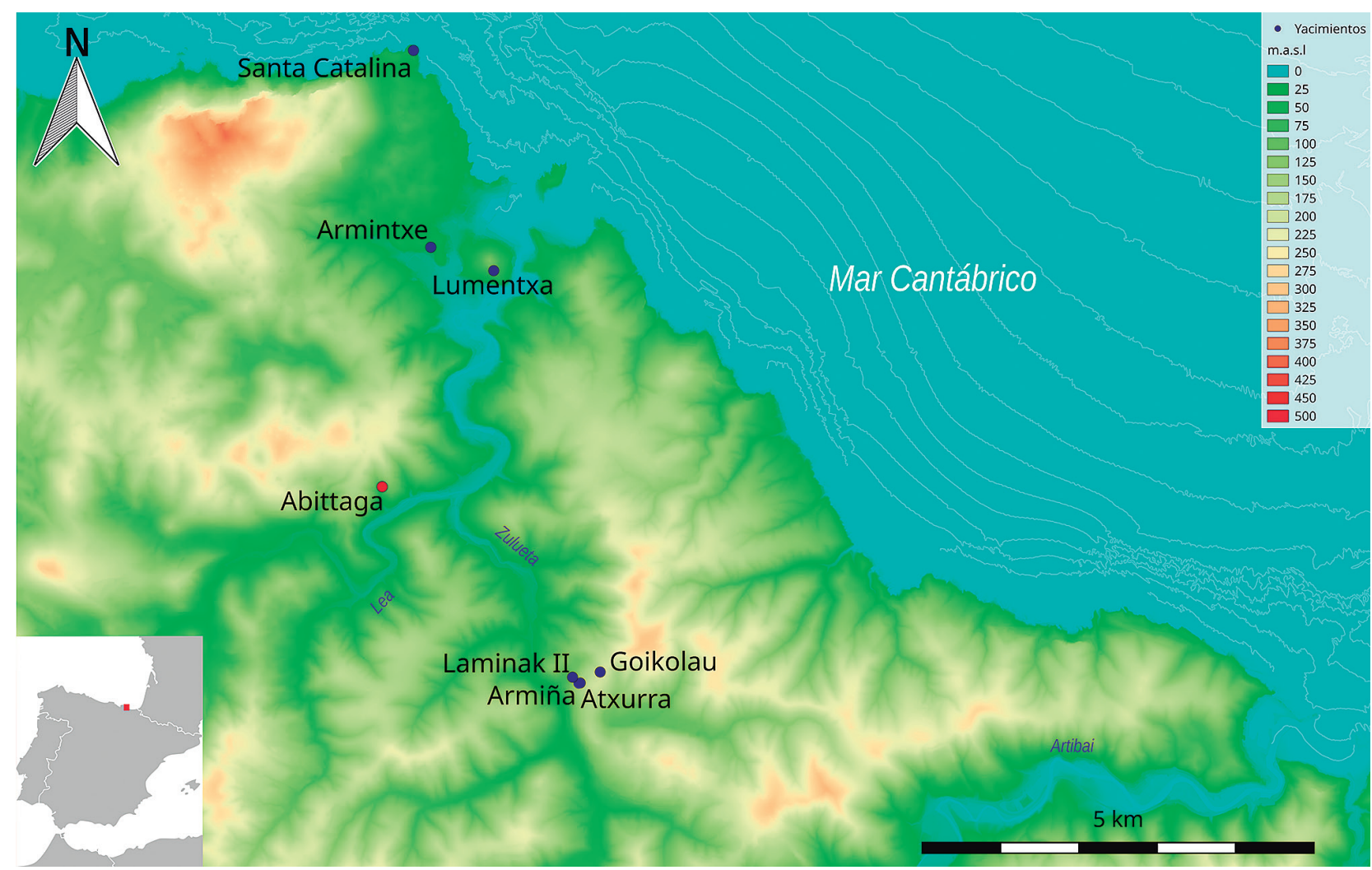

Fig.1. Mapa de localización de Abittaga y de los otros yacimientos de la cuenca del Lea mencionados en el texto. / Map of Lea basin with the position of Abittaga and other sites mentioned in the text.

el mantenimiento de amplias redes de contacto entre los grupos que habitan la región cántabro-pirenaica en esta época, o durante la Prehistoria Reciente. Sin embargo, el estado actual de la documentación de buena parte de los yacimientos excavados con anterioridad a 1980 no es adecuado para responder a estas cuestiones y, tal y como hemos mostrado con las excavaciones de J.M. Barandiarán en la cueva de Atxurra, es necesario la revisión sistemática de las excavaciones y colecciones antiguas para intentar obtener una información de mayor calidad (Rios-Garaizar et al., 2019).

En línea con este planteamiento en el año 2016 se abordó, bajo la coordinación de A. San Emeterio, el estudio de la colección arqueológica procedente de las excavaciones de J.M. Barandiarán y se realizó una pequeña intervención arqueológica en la cueva con el objetivo de documentar un posible testigo estratigráfico en la primera sala del yacimiento. En este trabajo se presentan los resultados de esta revisión.

\section{LA CUEVA DE ABITTAGA}

La cueva de Abittaga (Amoroto, Bizkaia) se sitúa a 96 metros sobre el nivel del mar y 85 metros sobre el cauce actual del río Lea (UTM 30: X: 539337, Y: 4798906, Z: 96), en una zona de calizas urgonianas del Cretácico Inferior. La entrada tiene pequeñas dimen- siones, $1,5 \times 3,5 \mathrm{~m}$, y se encuentra parcialmente colmatada por un cono de derrubios que desciende hacia el interior del vestíbulo. La entrada enlaza con una galería principal descendente de amplias dimensiones que se bifurca a unos 100 metros para continuar formando una extensa red de galerías que llega a alcanzar los 5000 m de desarrollo en varios niveles (Garate, 2012).

El área de actuación de J.M. Barandiarán se circunscribió a la zona central del vestíbulo de la cueva, a 4 metros de la entrada y pegada a la pared derecha. La superficie excavada abarcó un total de 13 cuadros, donde se documentaron siete niveles arqueológicos (Barandiarán, 1969, 1971) que buzan hacia el interior de la cavidad llegando a roca madre únicamente en los cuadros pegados a la pared derecha. Como resultado de esta excavación se recupera una secuencia de siete niveles (I-VII) (S1). En 1970, J.M. Apellániz amplía el área de excavación precedente. A partir de las notas y planos conservados en el Arkeologi Museoa se ha podido reconstruir la extensión de la excavación y la estratigrafía observada. Se constata que J.M. ApeIlániz no llega a localizar la secuencia excavada por J.M. Barandiarán (S2). En la intervención de 2016 se excavaron los cuadros C9 y C11 correspondientes a la cuadrícula de J.M. Barandiarán. Se documentaron tres unidades estratigráficas, y sólo en la Unidad 2b se recuperó algo de material que parece corresponder con 

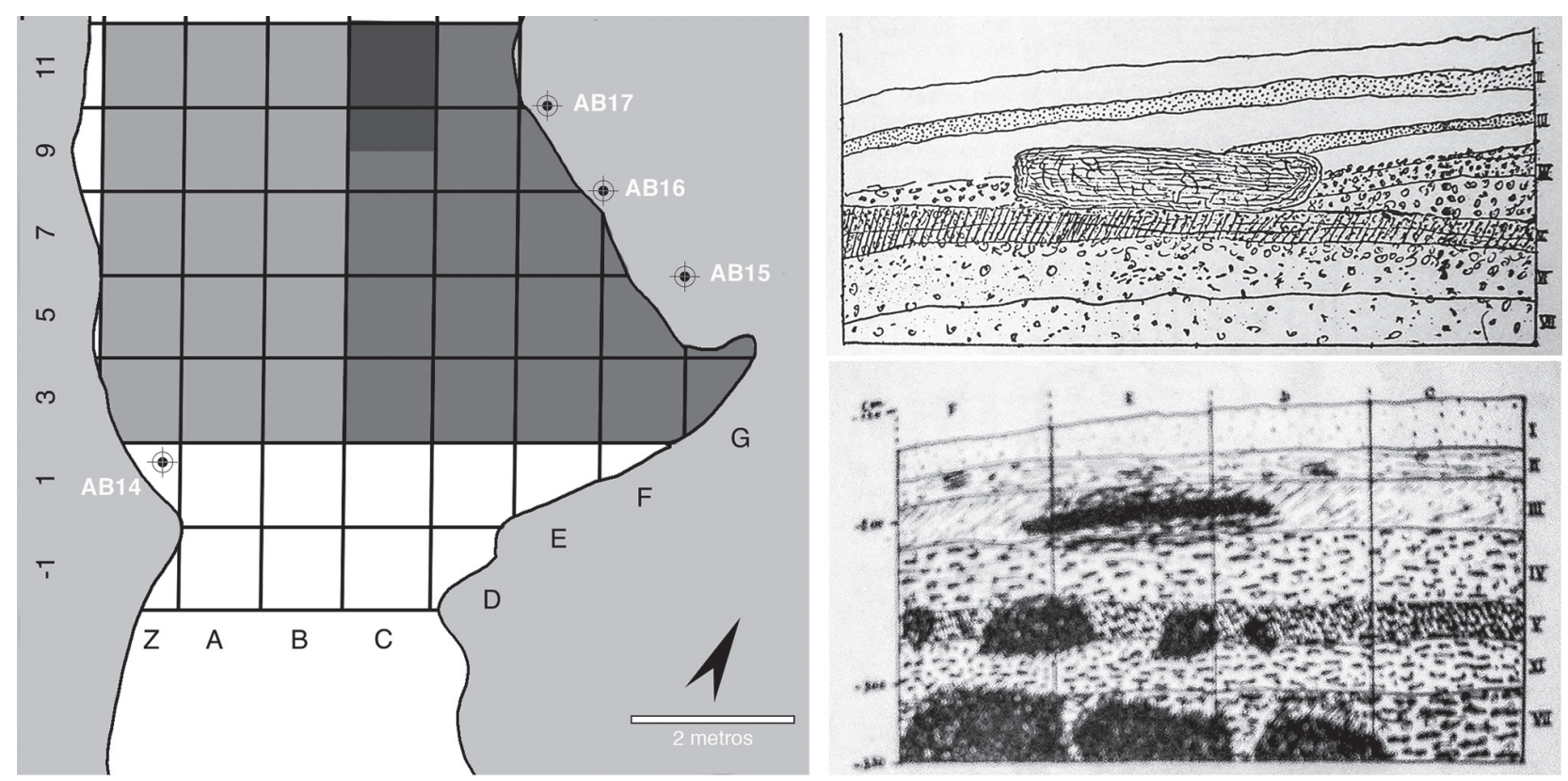

Fig.2. Plano (a partir de Garate, 2012) con la zona intervenida por Barandiarán (gris medio), la zona intervenida por Apellániz (gris claro) y la zona excavada en 2016 (gris oscuro). Sección estratigráfica de Abittaga en la banda 5 (Barandiarán, 1969- arriba- y 1971- abajo). / Plan (modified from Garate, 2012) with the location of Barandiarán (medium gray), Apellániz (light gray), and 2016 (dark gray) excavations. Abittaga stratigraphic section in band 5 (Barandiarán, 1969- up- y 1971- down).

el nivel VII de la excavación de J.M Barandiarán (S3). Dos muestras de hueso procedentes de las excavaciones de J.M. Barandiarán, una del nivel II y otra del VII, han proporcionado resultados que permiten encuadrar los niveles superiores en la Edad del Bronce (un resto humano datado en 1895-1689 cal. BC; Ua-64120), y el nivel VII en el Magdaleniense Superior (un metápodo de ungulado con huellas de corte datado en1432114051 cal. BP; Beta-457783) (S4, Tabla S4.1).

\section{REVISIÓN DE LA COLECCIÓN DE J.M. BA- RANDIARÁN}

La colección arqueológica de la excavación de Abittaga realizada por J.M. Barandiarán (1964 y 1966) está depositada en el Arkeologi Museoa (Bilbao) y la componen tres elementos macrolíticos (S5, Figura S5.1), 710 elementos líticos tallados (S6), 106 fragmentos cerámicos aislados y dos recipientes parcialmente reconstruidos (S7), 11 elementos de industria ósea, 238 restos de fauna y 32 restos antropológicos (S8).

\subsection{Industria lítica}

El conjunto lítico de la cueva de Abittaga está compuesto por un total de 710 restos (S6, Tablas S6.1-3), de los cuales solamente cuatro son esquirlas menores de $1 \mathrm{~cm}$, tres son fragmentos informes, dos son lascas térmicas y uno un bloque bruto de sílex sin tallar (Tabla S6.3). Asimismo, se han documentado tres cantos con huellas de utilización (Figura S5.1).
En el Nivel I se han documentado solamente nueve restos líticos y ninguno de ellos retocado. Destaca la presencia de un canto de ofita o basalto en el que se interpretó una representación esquemática de una cabra (Fernández Ibáñez, 1986), que se atribuyó al Ilamado arte esquemático del País Vasco (Llanos, 1966). La revisión de la pieza nos permite plantear dudas acerca de esta interpretación (S5 y Figura S5.1: 1). En los niveles II y III apenas se han recuperado ocho y 13 restos respectivamente.

En el Nivel IV sólo se han recuperado seis restos. En el Nivel V sólo tres soportes laminares han sido atribuidos con seguridad al nivel, uno de ellos está retocado como muesca. En el Nivel VI se ha recuperado un conjunto de 28 restos líticos, con más lascas que láminas, y productos de acondicionamiento de núcleos laminares. Además, hay dos muescas, una pieza de dorso y una lámina parcialmente retocada.

En el Nivel VII se concentra el grueso de la colección, con un total de 639 restos. El sílex supone el 99,21\% del conjunto, destacando el sílex del Flysch, generalmente de calidad mediocre, el de Urbasa y una variedad de sílex indeterminado que está diaclasado y que probablemente tenga su origen en las propias calizas urgonianas (Tabla S6.2). Otras variedades como Treviño, Loza, Chalosse o Bidache aparecen en proporciones muy modestas. Además, una parte de conjunto no ha podido ser atribuido a ninguna variedad en concreto. Otras materias como la lutita, el cuarzo y la ofita son testimoniales. Aunque el material está bien conservado, 34 soportes muestran alteraciones térmi- 


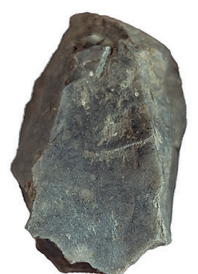

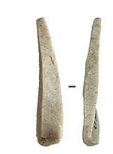

2. 1

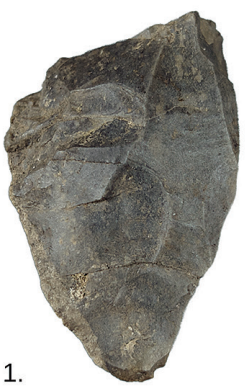

1.

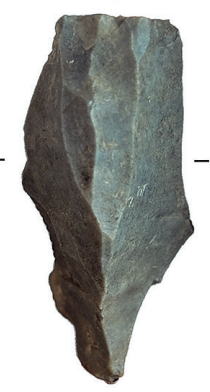

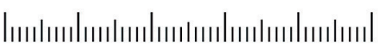
6. CENIEH labs@cenieh.es
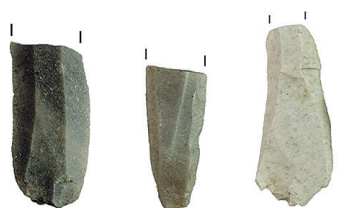

18.1

19. 1

20. 1
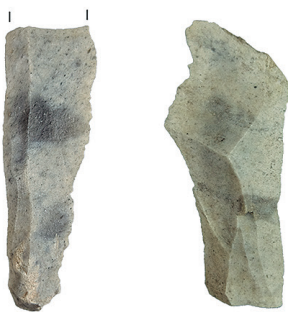

23. 12.

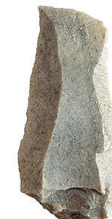

21. 1

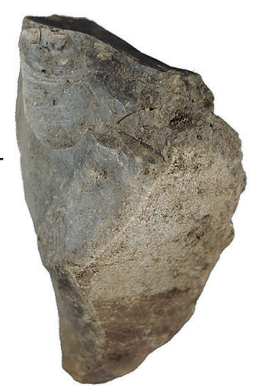

9. 1 10.

24.

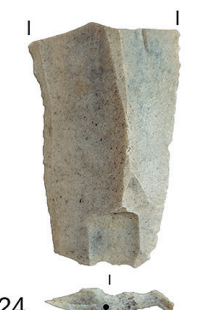

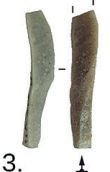

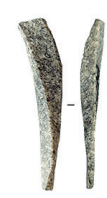

4. 1
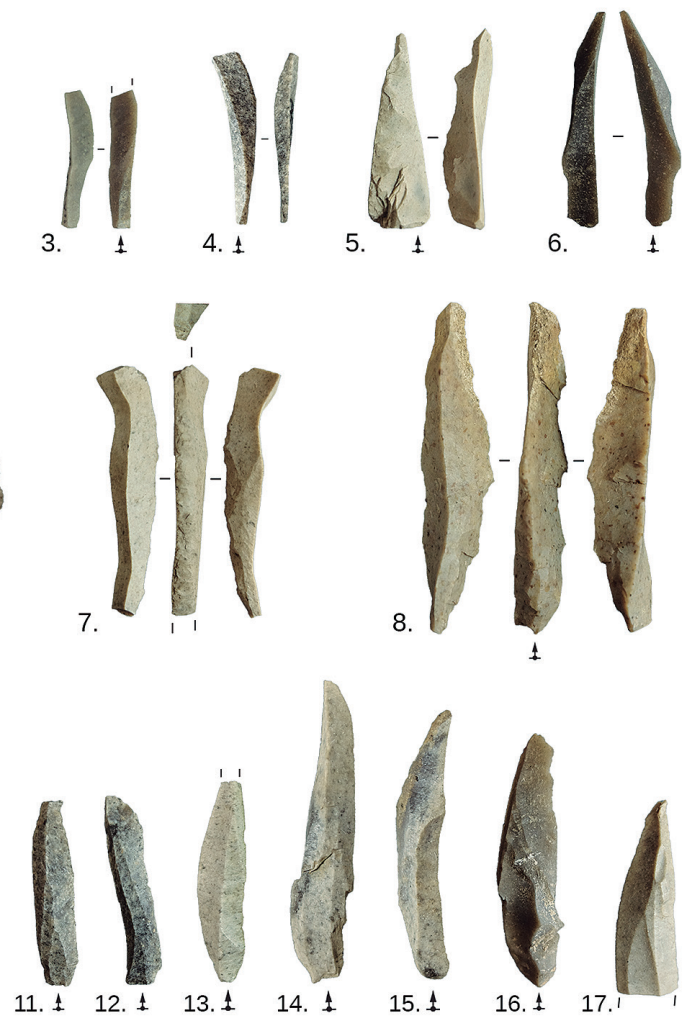

13. 1
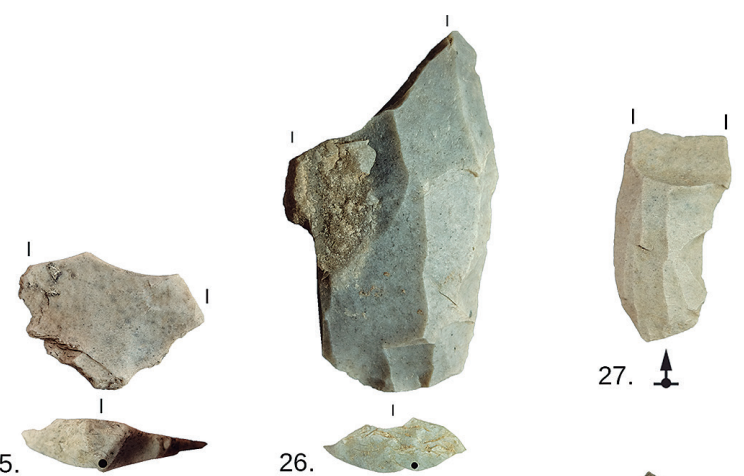

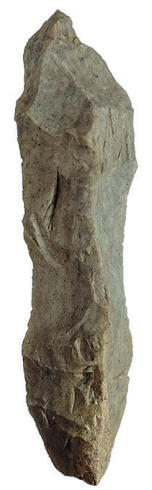

34. 1

28.
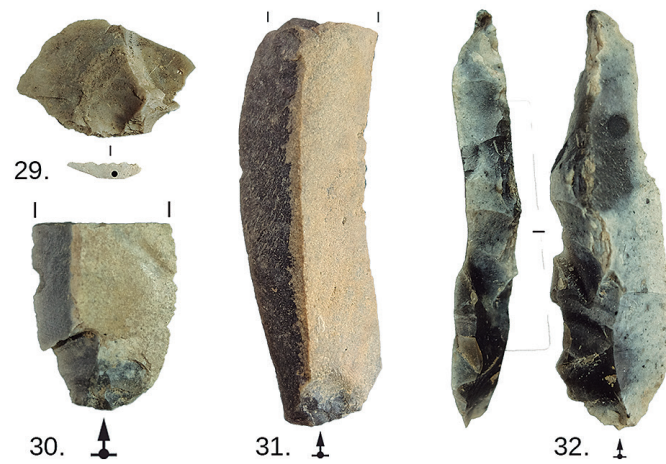

33. 1
32. 1
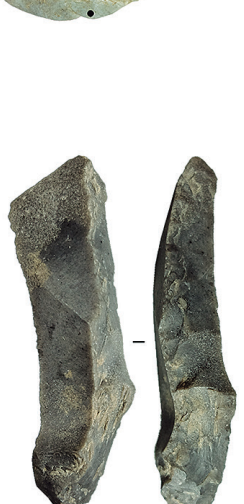

27. 1

Fig.3. Restos líticos del Nivel VII. 1 Núcleo de laminillas sobre filo de lasca, tipo buril, 2-8 Golpes de buril, 9-21 Laminillas, $22-24$ Láminas,
25 Tableta de reavivado, 26-27 Limpiezas de cara de lascado, 28 Lámina sobrepasada, 29 Lasca, 30-31 Láminas corticales, $32-33$ Crestas unifaciales, 34 Cresta bifacial. / Lithic artefacts from level VII. 1 Burin like on-flake-edge bladelet core; 2-8 Burin spalls; 9-21 Bladelets; $22-24$ Blades; 25 Platform rejuvenation flake; 26-27 Flaking surface rejuvenation flakes; 28 Overshot blade; 29 Flake; 30-31 Cortical blades; $32-33$ One side crested blades; 34 Two side crested blades. 

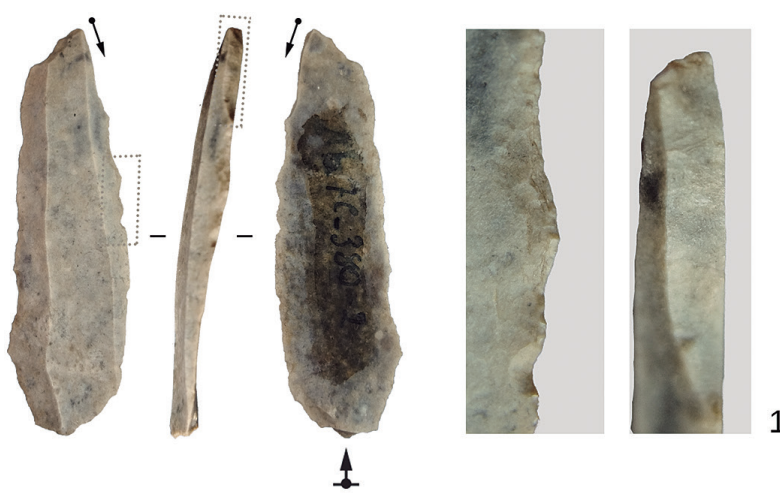

1.

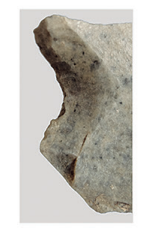

3.
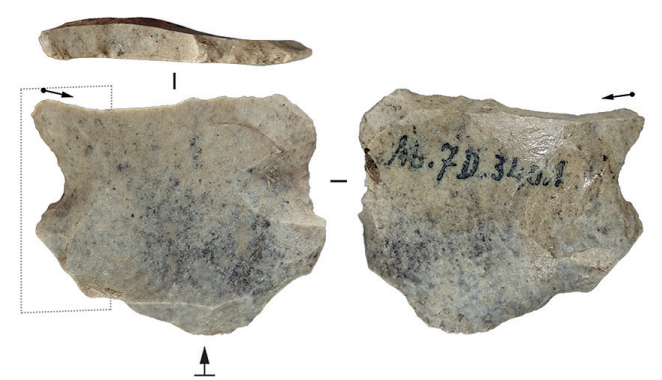

1
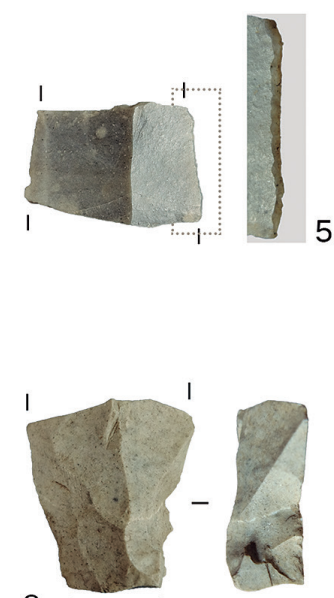

8. 1

5.
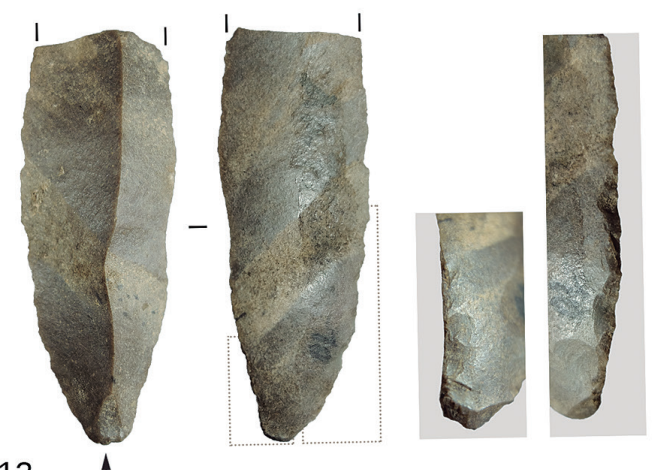

12
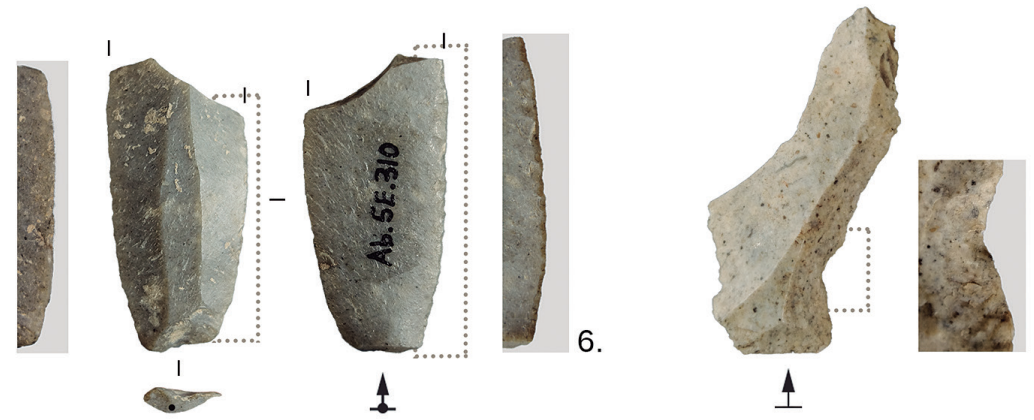

7.

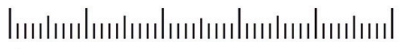

S. labs@cenieh.es

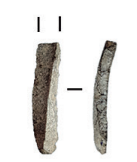

9. 1

10. 1

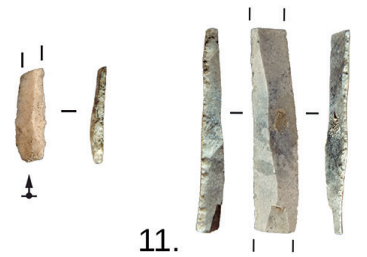

Fig.4. Utillaje lítico retocado del Nivel VII. 1-4 Buriles, 5-6 Piezas de dorso, 7-8 Piezas de muesca, 9-11 Laminillas de dorso, 12-13 Útiles diversos (lámina con retoque inverso en la base, y lámina pedunculada). / Retouched tools from level VII. 1-4 Burins; 5-6 Marginally backed blades; 7-8 Notched blades; 9-11 Backed bladelets; 12-13 Diverse tools (blade with ventral retouch in the proximal part and tanged blade). 
cas relacionadas probablemente con los hogares descritos en los cuadros 5D, 5E y 5F (Barandiarán, 1971).

La composición del conjunto está dominada por los soportes brutos, especialmente los soportes laminares, con más laminillas que láminas (Tabla S6.3). Las labores de mantenimiento de los núcleos laminares tienen cierto peso en este conjunto a juzgar por la importancia numérica y la variedad de productos de acondicionamiento, lo cual contrasta con la escasez de núcleos. Los productos de acondicionamiento proceden principalmente de núcleos de laminillas de pequeño tamaño. Los soportes de decorticado presentan proporciones discretas, al igual que los productos de reavivado de útiles, aunque dentro de estos destacan los golpes de buril.

Los núcleos son escasos $(n=3)$, siendo uno de ellos de lasquitas sobre lasca, y los otros dos son núcleos de laminillas, uno sobre nódulo de sílex del Flysch (Figura S6.1: e) y el otro sobre lasca cortical espesa (Figura 4: 1). Esta escasez de núcleos de laminillas, cuando éstas son el objetivo prioritario de la talla, puede explicarse por la abundancia de buriles espesos, que presentan múltiples paños y reavivados y que pueden representar otro modelo de explotación laminar (Le Brun-Ricalens y Brou, 2003).

Entre los productos destaca un conjunto de láminas de buen tamaño obtenidas a partir de núcleos con un flanco muy marcado (generalmente a la izquierda y tallados), caras de lascado triangulares y bastante estrechas, y correcciones mediante una cresta o semicresta distal, que no aparece reflejada en los núcleos documentados, pero sí en algunas laminillas que la arrastran en su zona distal.

El número de útiles retocados asciende a 52, lo que supone un $8,14 \%$ del utillaje, porcentaje muy bajo para un nivel arqueológico en cueva, algo que puede estar relacionado con la funcionalidad de las ocupaciones (Tabla S6.4). Además de la escasez del utillaje retocado, este nivel destaca también por la escasa variedad de los tipos representados: dominando ampliamente en el conjunto el grupo de los buriles, el del utillaje de sustrato y el grupo de los diversos. El grupo de los diversos está compuesto fundamentalmente por láminas parcialmente retocadas en la zona proximal y en los filos proximales, estos retoques pueden responder a un acondicionamiento para el enmangue (Figura 4: 12-13). También aparecen bien representados el grupo de las hojitas retocadas, los perforadores y las piezas de dorso. A la vez que destaca la total ausencia del grupo de los raspadores y de las piezas astilladas (Tabla S6.4).

Además, en el nivel VII se ha documentado un fragmento de canto de ofita que presenta un negativo de una extracción además de huellas de piqueteado en el contorno y con algunas zonas de su superficie abrasionadas (Figura S5.1:2), y un compresor sobre un canto alargado de lutita (Figura S5.1:3). En cuanto al compresor presenta la zona distal activa en ambas caras con abundantes y profundas huellas de uso. En el extremo opuesto también presenta ciertas marcas de uso, pero mucho menos intensas.

\subsection{Industria ósea}

La industria ósea recuperada en los niveles VI y VII fue revisada y publicada por C. González Sainz que realizó una breve descripción de los útiles óseos de este yacimiento (González Sainz, 1983). Posteriormente ha sido reanalizada en el marco de una tesis de máster (Larrea Robles, 2017). La práctica totalidad del conjunto descrito por J.M. Barandiarán (Barandiarán, 1969, 1971) se encuentra en el Arkeologi Museoa, pero algunas piezas significativas no se han podido localizar en sus fondos, especialmente un fragmento de "punzón" decorado del nivel VII (Barandiarán, 1971: Fig. 17:3) que ya estaba perdida cuando C. González Sainz realizó su estudio (González Sainz, 1983).

En el Nivel VI se ha recuperado un fragmento pequeño $(21 \times 16 \times 5 \mathrm{~mm})$ de hueso de sección plano-convexa con pulimento en las dos caras (Figura 5: 6), y un fragmento mesio-distal $(78 \times 20 \times 8 \mathrm{~mm})$ de varilla realizada sobre asta (Figura 5: 8). La varilla tiene sección plano-convexa, con bordes paralelos, el extremo distal apuntado y perfil curvo. Presenta, además, tres incisiones paralelas, posiblemente decorativas, en forma de "S" que nacen del borde izquierdo y otra incisión longitudinal casi paralela al borde derecho. El soporte se obtuvo mediante la técnica del doble ranurado, mientras que la finalización se realizó por pulido, en función de las estrías finas que se observan en la superficie. La fractura proximal es neta, y probablemente se debe a procesos postdeposicionales, mientras que la fractura de la zona distal fue por flexión.

En el Nivel VII se han recuperado seis azagayas sobre asta, ninguna de ellas completa, y tres fragmentos de arpones de sección circular y una hilera de dientes. Las azagayas presentan distintos tipos de secciones (dos cuadrangulares, una rectangular y tres circulares). Las técnicas de fabricación incluyen el ranurado y la flexión para la obtención de soportes, el raspado y el pulido. Algunas de las piezas parecen plenamente terminadas frente a otras en las que no se han eliminado las zonas exteriores de la asta o el tejido esponjoso. El fragmento más completo presenta un base en pedúnculo con surcos transversales, posiblemente relacionados con la fabricación (Figura 5: 7). Ninguna de las piezas presenta decoración. Todas las azagayas están fracturadas, dos de ellas presentan claras fracturas postdeposicionales, mientras que cinco muestran fracturas que son compatibles con el uso. Así, una de las azagayas de grandes dimensiones $(136 \times 13 \times 10 \mathrm{~mm})$ muestra una fractura distal, "en charnière" (Pétillon, 2000: 36) y desconchados en el extremo del bisel que sugieren una fractura por impacto (Figura 5: 7). Dos de los fragmentos de azagayas circulares presentan fracturas en lengüeta profundas que sugieren una fractura en flexión por impacto (Figu- 

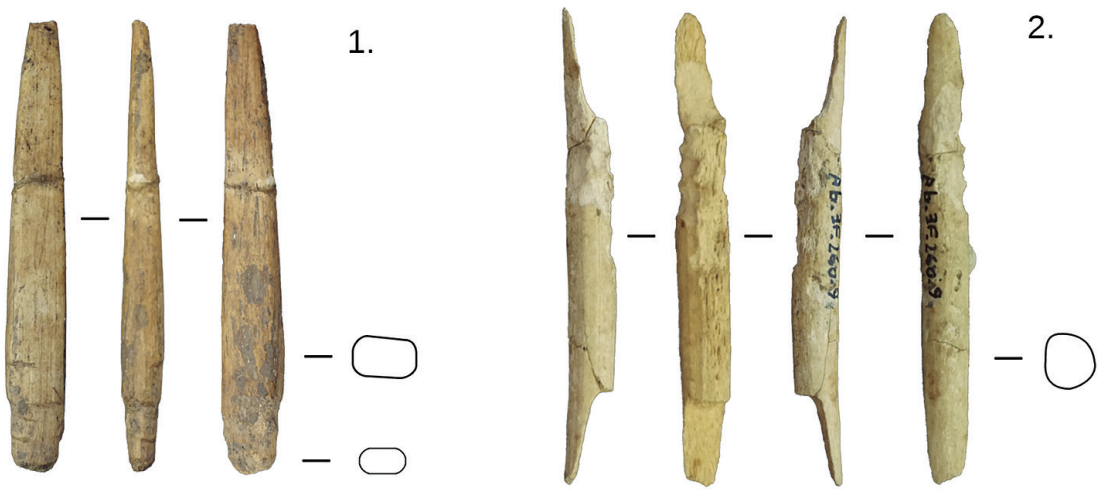

3.
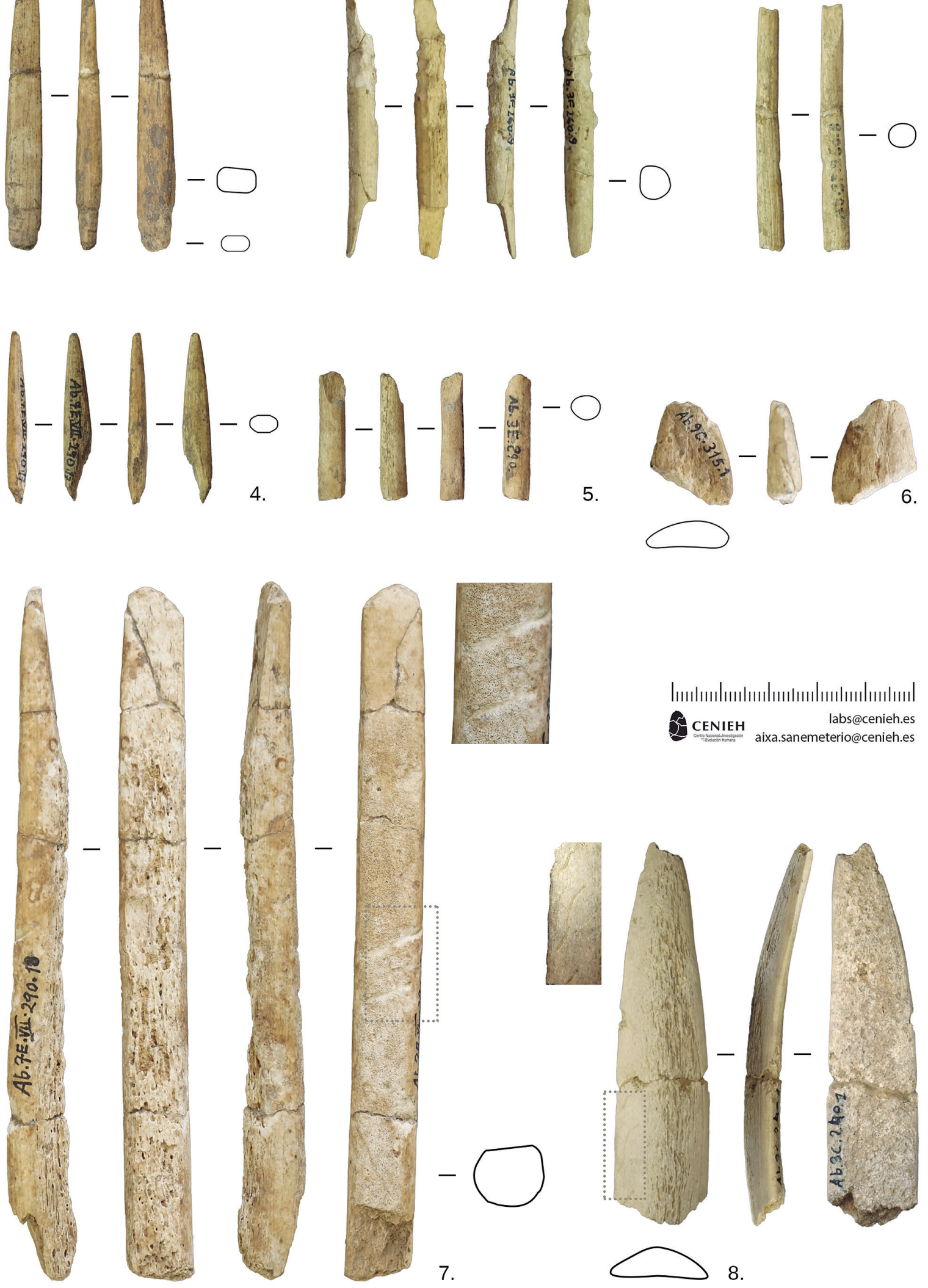

Fig.5. 1-5 y 7. Azagayas del nivel VII. 6. Fragmento óseo pulido del Nivel VI y 8. Varilla del nivel VI. / 1-5 and 7 Bone points from level VII; 6 Polished bone fragment from level VI; 8 Bone rod from level VI. 


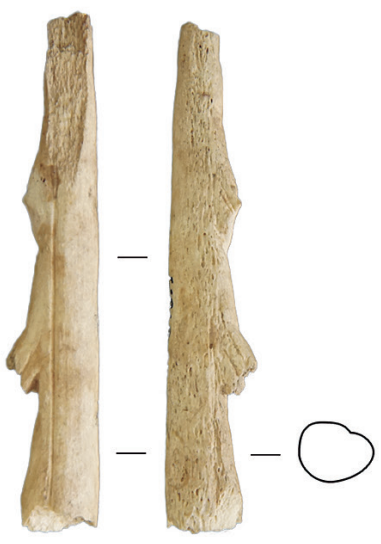

1.
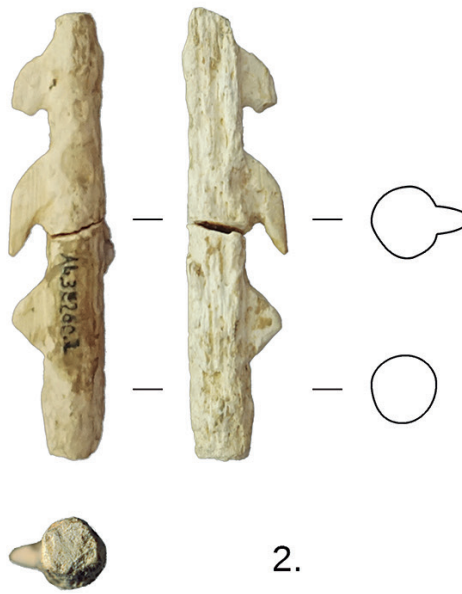

2.
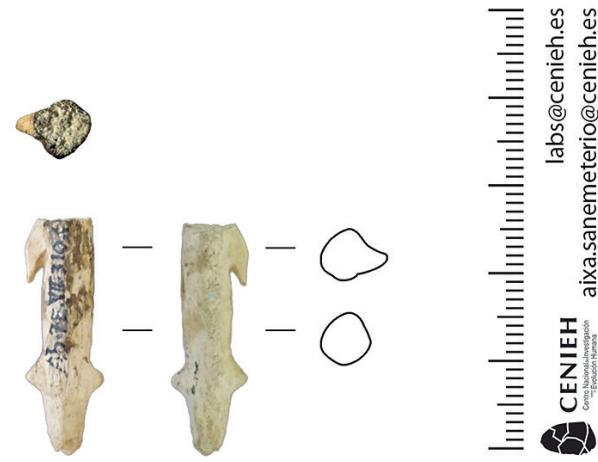

3.

Fig.6. Arpones del Nivel VII. / Harpoons from level VII

ra 5: 3 y 5). La azagaya de sección rectangular (34 x 6 $\times 4 \mathrm{~mm}$ ) presenta un embotamiento de la punta como consecuencia del uso (Muñoz y San Nicolás, 2010) y una fractura en la zona proximal por flexión que sugiere una fractura por impacto (Figura 5: 1). Finalmente, un fragmento mesial de azagaya de sección circular (57 $\times 6 \times 5 \mathrm{~mm}$ ) presenta dos aletas en los extremos que permiten proponer la presencia de un útil biahorquillado (González Sainz, 1983), por lo que habría que interpretar la pieza como un préhampe (Pétillon y Cattelain, 2004). La pieza está muy alterada y presenta alteraciones postdeposicionales por mordisqueo (Figura 5: 2). Los fragmentos de arpones son todos de sección circular y con una sola hilera de dientes. Uno de los arpones (56 × $8 \times 7 \mathrm{~mm})$ no conserva ni la punta ni la base, presentando el extremo distal una fractura en lengüeta por flexión, probablemente producida como resultado de un impacto (Figura 6: 1). Esta pieza presenta además una acanaladura central, lo que puede considerarse como un motivo decorativo o más bien como un acondicionamiento para insertar laminillas de sílex. Los otros dos arpones conservan la base, uno de ellos con un abultamiento doble $(26 \times 6 \times 6 \mathrm{~mm})$ y el otro con abultamiento simple $(49 \times 6 \times 6 \mathrm{~mm})$. En ambos casos las piezas presentan fracturas de origen postdeposicional. Estos arpones muestran huellas de fabricación que indican el uso del raspado y del pulido para la configuración del fuste, mientras que la elaboración de los dientes se ha ejecutado mediante incisión y raspado (Muñoz y San Nicolás, 2010).

\subsection{Cerámica}

El conjunto cerámico está formado por 106 fragmentos cerámicos aislados y dos recipientes parcialmente reconstruidos a partir de 53 fragmentos (recipiente 1) y 23 (recipiente 2) (S7, Tabla S7.1). Todo este material fue ya documentado por J. M. Barandiarán (Barandiarán, 1969, 1971).
Sin adscripción. El conjunto cerámico que no cuenta con adscripción estratigráfica asciende a un total de 27 fragmentos (Tabla S7.1). Todos ellos están realizados a mano con un predominio de las condiciones de cocción alternantes $(n=17)$ frente a las reductoras $(n=$ $4)$ y oxidantes $(n=6)$. Atendiendo a su morfología, el conjunto está dominado por los galbos convexos ( $n=$ $19)$, seguidos por los indeterminados $(n=6)$ y galbos indeterminados $(n=2)$, en su mayoría lisos, aunque se ha observado la presencia de adhesiones de barro plástico con impresiones en las superficies externas $(n=4)$.

Nivel I. El conjunto cerámico adscrito al nivel I y I? (Tabla S7.1) asciende a 39 fragmentos caracterizados por un predominio de las cocciones en atmósfera alternante $(n=36)$ frente a las reductoras $(n=2)$ y oxidantes $(n=1)$. Atendiendo a la morfología, el conjunto está constituido por los galbos convexos $(n=19)$ e indeterminados $(n=15)$. Los fragmentos de galbo indeterminado $(n=2)$ y borde $(n=3)$ constituyen una minoría dentro del conjunto (Figura 7). Los fragmentos de borde identificados presentan una morfología redondeada convexa con direccionalidades vueltas al interior $(n=2)$ o rectas $(n=1)$ (Figura 7$)$. Todos los fragmentos adscritos al nivel I son lisos, estando completamente ausentes los motivos decorativos. Únicamente se ha documentado la presencia de barro plástico con impresiones en las superficies externas de algunos fragmentos $(n=4)$.

Nivel II. Los fragmentos adscritos al nivel II ( $n=$ 19; Tabla S7.1) están realizados a mano, aunque en un caso se han identificado trazas tecnológicas relacionadas con el posible uso del torno lento. La atmósfera de cocción más representada es la alternante ( $n$ =13), seguida de la oxidante $(n=4)$ y reductora ( $n$ $=2$ ). Morfológicamente, el conjunto refleja un predominio de los galbos convexos $(n=12)$ con la presencia de indeterminados $(n=2)$, galbos indeterminados ( $n$ $=1)$, fragmentos de base $(n=3)$ y una fusayola. Las bases son planas con diámetros de 110, 130 y 140 mm 
NIVEL I
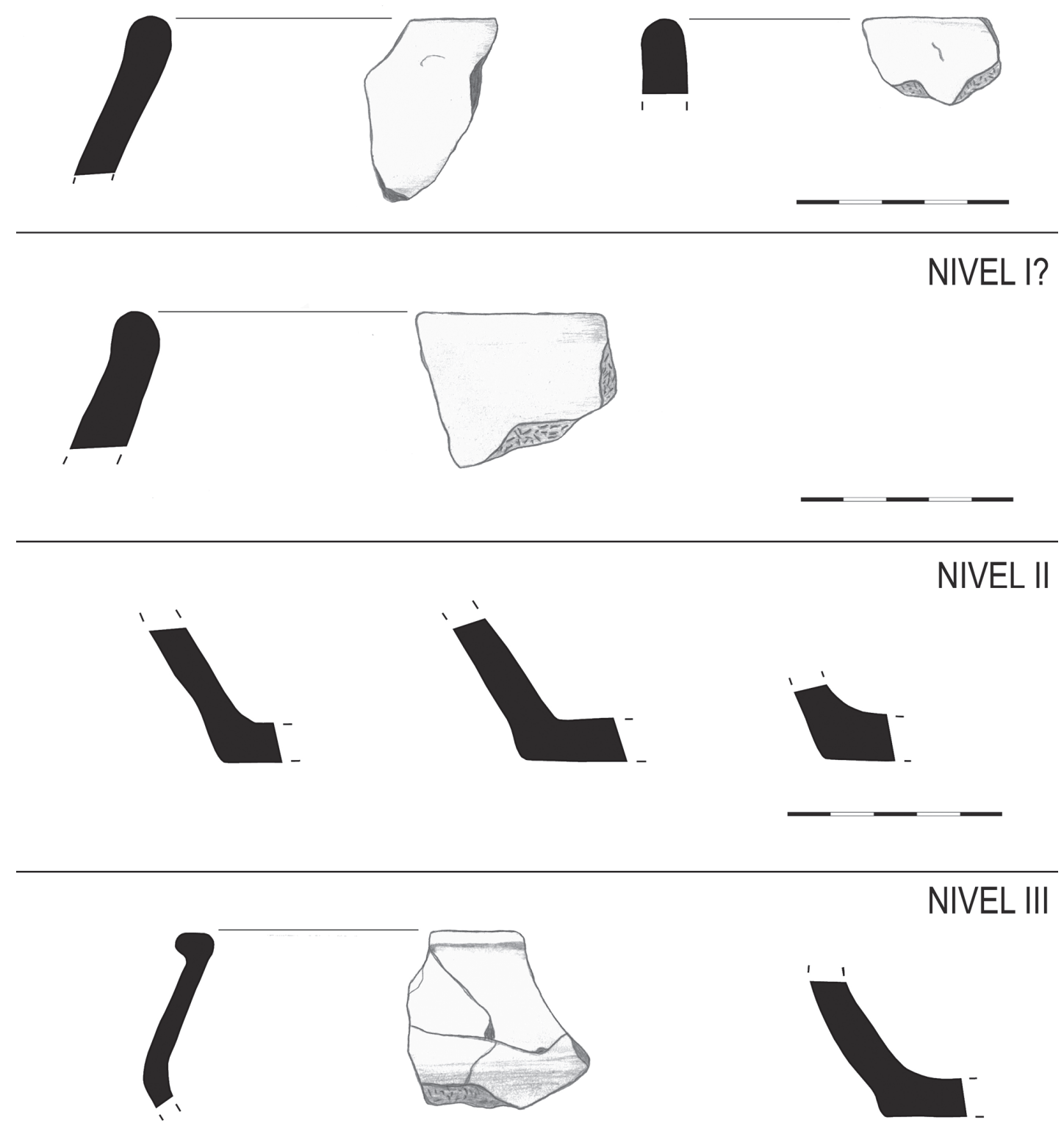

NIVEL III

Fig.7. Fragmentos morfológicamente representativos de los distintos niveles arqueológicos. / Representative morphological pottery sherds from different archaeological levels.

y, en algunos casos, ligeramente indicadas (Figura 7). Posiblemente, el elemento más destacado a nivel morfológico es la fusayola circular con perforación central (Figura 8: C). A nivel decorativo, se han identificado dos fragmentos con cordones plásticos adheridos dispuestos en horizontal. En un caso se observa la presencia de una perforación postcocción en un fragmento de galbo posiblemente relacionada con las labores de reparación del recipiente cerámico.
Nivel III. El conjunto adscrito al nivel III asciende a 21 fragmentos (Tabla S7.1) realizados a mano con una coloración característica de una atmósfera alternante no habiéndose observado coloraciones relacionadas con una cocción en atmósfera oxidante o reductora. Atendiendo a su morfología, se observa un predominio de los galbos convexos $(n=14)$ y carenados $(n=2)$ con una escasa representación de los galbos indeterminados $(n=2)$, indeterminados $(n=1)$, bordes $(n=1)$ 
y base $(n=1)$. Los fragmentos de galbo convexo y el borde permiten reconstruir una sección del perfil de un pequeño cuenco cerámico cerrado, con carena en la parte media, y borde exvasado y redondeado (Figura 7, nivel III). Por último, se ha identificado la adhesión de barro plástico con impresiones en la superficie externa de los fragmentos $(n=4)$ y una pequeña perforación postcocción en un fragmento de galbo que podría estar relacionada con la reparación del recipiente cerámico.

Los recipientes cerámicos. Durante los años 1990, se procedió a la reconstrucción de dos recipientes que actualmente se encuentran en el Arkeologi Museoa. El denominado "recipiente 1" está constituido por 53 fragmentos (Figura 8: A) adscritos estratigráficamente a los tres niveles de la parte superior de la secuencia documentada en el yacimiento (Tabla S7.1). Actualmente el recipiente presenta un perfil reconstruido de 15,6 cm. Presenta una manufactura a mano y una coloración que denota unas condiciones de cocción alternantes. En ambas superficies se han observado trazas tecnológicas relacionadas con el alisado. Este recipiente presenta una morfología ovoide, de perfil simple cuya parte superior se caracteriza por un borde de direccionalidad recta y morfología plana. Los diámetros conservados son muy similares en la parte superior $(17 \mathrm{~cm}$ de diámetro en el borde) y en la parte media $(18 \mathrm{~cm}$ en la parte central del galbo). La decoración presenta un patrón simple, formado por dos cordones plásticos adheridos paralelos al borde.

Por su parte el "recipiente 2" está constituido por 23 fragmentos (Tabla S7.1; Figura 8) procedentes de los niveles I y II. Actualmente, el recipiente cuenta con una altura de $92,08 \mathrm{~mm}$ y un grosor medio de los fragmentos de 8,36 mm. Las superficies internas están regularizadas, mientras que las externas reflejan trazas tecnológicas relacionadas con el alisado. A pesar de que únicamente se conserva una parte del tercio superior del recipiente, parece observarse una morfología ovoide, de perfil simple con un borde de direccionalidad recta y labio de morfología redondeada convexa. El diámetro superior es irregular y se sitúa entre los 17-20 cm, similar al diámetro de la zona superior del galbo. Se trata de un recipiente completamente liso, sin motivos decorativos.

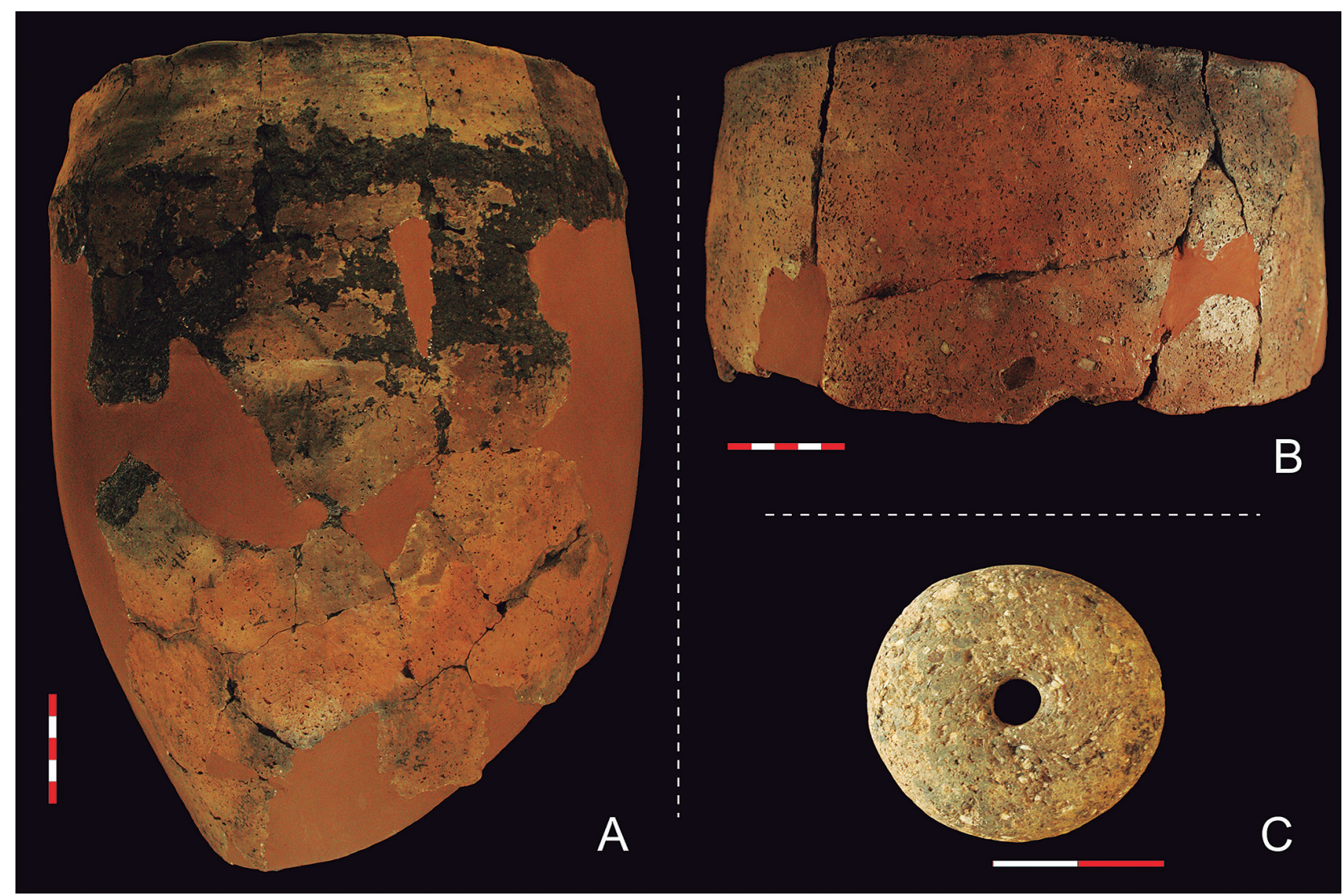

Fig.8. A) Recipiente 1 en el que remontan fragmentos procedentes de los tres niveles superiores (I, II y III). B) Recipiente 2 que incluye fragmentos procedentes de los niveles I y II. C) Fusayola identificada en el nivel II. / A. Vessel 1 refitted from pottery sherds recorded in the three upper archaeological levels (I, II and III). B). Vessel 2 with pottery sherds recorded in levels I and II. C) Spindle whorl recorded in level II. 


\subsection{Fauna}

En la Tabla S8.1 se muestran el número de restos de aves, macromamíferos, peces y moluscos ordenados por niveles. La mayor parte de los 238 restos de las excavaciones antiguas se recuperaron en el nivel I $(n=127)$ y VII $(n=35)$. Los 32 restos de aves pertenecen a un mínimo de tres taxones: un anseriforme indeterminado, y al menos dos especies de córvidos. La chova piquirroja (Pyrrhocorax pyrrhocorax) es la especie más representada del conjunto de aves. En el caso de los macromamíferos, los herbívoros son mayoritarios, mientras que apenas existen tres restos de carnívoros. En los niveles pertenecientes al Holoceno (niveles I-III) predominan los restos de ovicápridos, con la presencia de cerdo/jabalí (Sus sp.), un gato (Felis sp.) y un resto de cánido (Canis sp.). En los niveles del Pleistoceno se han recuperado restos de rebeco (Rupicapra pyrenaica), de cabra montés (Capra pyrenaica), de ciervo (Cervus elaphus) y el único resto de carnívoro se trata de un fragmento de hemimandíbula derecha de gato montés (Felis silvestris). También se han recuperado cinco vértebras de pez de los niveles inferiores (VI y VII). Los restos de malacofauna se han recuperado principalmente en los niveles superiores I-IV, siendo las lapas (género Patella) los restos mejor representados. Destaca la presencia en los niveles inferiores, V y VII de abundantes ejemplares del gasterópodo Littorina obtusata, que aparte del escaso interés bromatológico, pueden indicar su recolección para fabricar objetos de adorno (frecuentes en el Magdaleniense). Por último, indicar la presencia de restos de microfauna, que se limitan al nivel I (cuadros 9Z, 11C-D y 11Z) y que incluye (al menos) tanto restos del Orden Rodentia así como del Orden Eulipotyphla.

\subsection{Restos humanos}

Se ha contabilizado un total de 32 restos humanos, que comprenden dos dientes, cuatro vértebras, dos clavículas, un húmero, ocho metacarpianos, seis falanges de mano, cuatro metatarsianos y cinco falanges de pie (Tabla S8.2) (Figura 9). No hay duplicación de elementos óseos y son compatibles en términos de edad de muerte, por lo que representarían un único individuo adulto, de más de 29 años de edad de muerte al estar las epífisis esternales de las clavículas completamente fusionadas (Scheuer y Black, 2000). Se ha estimado una estatura comprendida entre los 153,0 y los 157,4 $\mathrm{cm}$ tomando como referencia la longitud máxima de los metatarsianos y metacarpianos, usando los métodos de Pablos et al., (2013) y Meadows et al., (1992) respectivamente. No se ha podido hacer una determinación sexual por falta de elementos diagnósticos, pero la estatura estimada para este individuo estaría por debajo de la media de los individuos determinados como mujeres del yacimiento de Txotxinkoba (García-Sagastibelza et al., en prensa). Esto sugiere que los restos de Abittaga, con todas las reservas debidas a la precaria representación anatómica y ausencia de elementos diagnósticos, podrían haber pertenecido a un individuo femenino. Una falange de mano (AB.7D.180.F) de este individuo ha sido datada directamente con un resultado de $3.478 \pm 36$ BP (Ua-64120, 1895-1690 cal BC, 95\% probabilidad) (Tabla S4.1.).

\section{DISCUSIÓN}

El yacimiento de Abittaga, al igual que otros excavados por J.M. Barandiarán como Atxurra o Lumentxa, ha contribuido de manera testimonial en los debates y discusiones sobre el Magdaleniense de la Región Cantábrica y en la discusión sobre el uso de las cuevas en la Prehistoria Reciente. Las causas de esta escasa relevancia, semejantes a las de otros conjuntos como Atxurra (Rios-Garaizar et al., 2019), son múltiples y tienen que ver con la escasa definición arqueológica de las secuencias excavadas, la falta de documentación detallada de los trabajos de campo, la ausencia de estudios y descripciones sistemáticas de los materiales, los problemas de conservación y la ausencia de datos cronológicos precisos.

Las primeras incógnitas surgen al contrastar los resultados de la excavación de J.M. Barandiarán (S1) con los de la excavación de J.M. Apellániz (S2) y con los resultados obtenidos en la intervención de 2016 (S3). Resulta sorprendente que en las dos últimas intervenciones apenas se recuperase material arqueológico y que todas las secuencias descritas sean diferentes. Si observamos la documentación proporcionada por J.M. Barandiarán, vemos que en las publicaciones de 1969 y 1971 se presentan dos secciones estratigráficas diferentes, ambas, en principio, procedentes del corte de la banda 5. Por otro lado, si situamos sobre el plano de la excavación la densidad de restos líticos del nivel VII vemos que se concentra en una banda de apenas $2 \mathrm{~m}$ paralela a la pared $\mathrm{E}$ de la cueva, el nivel V-VI apenas aparece en dos cuadros, al igual que el nivel IV. Esto nos lleva a plantear la hipótesis de que la secuencia paleolítica (niveles IV-VII) sólo estuviese conservada en una estrecha banda del depósito, pegada a la pared derecha, y que en la zona central e izquierda de la sala estos niveles no estuvieran conservados, posiblemente por erosión y transporte hacia el interior de la cueva. Esto explicaría por qué J.M. Apellániz no documentó el Magdaleniense (S1) y porqué en 2016, aunque se localizó una unidad asimilable a los niveles V-VII de J.M. Barandiarán (Unidad 2), no se recuperaron apenas materiales arqueológicos (S3).

El análisis de los restos arqueológicos recuperados por J.M. Barandiarán en la cueva de Abittaga entre 1964 y 1966 permite apuntar algunas cuestiones acerca de la integridad del yacimiento y de la validez de la secuencia estratigráfica. La información obtenida del estudio de la cerámica de los niveles I, II y III muestra que estos niveles presentan claras evidencias de remoción y que incorporan materiales de distintas cronolo- 


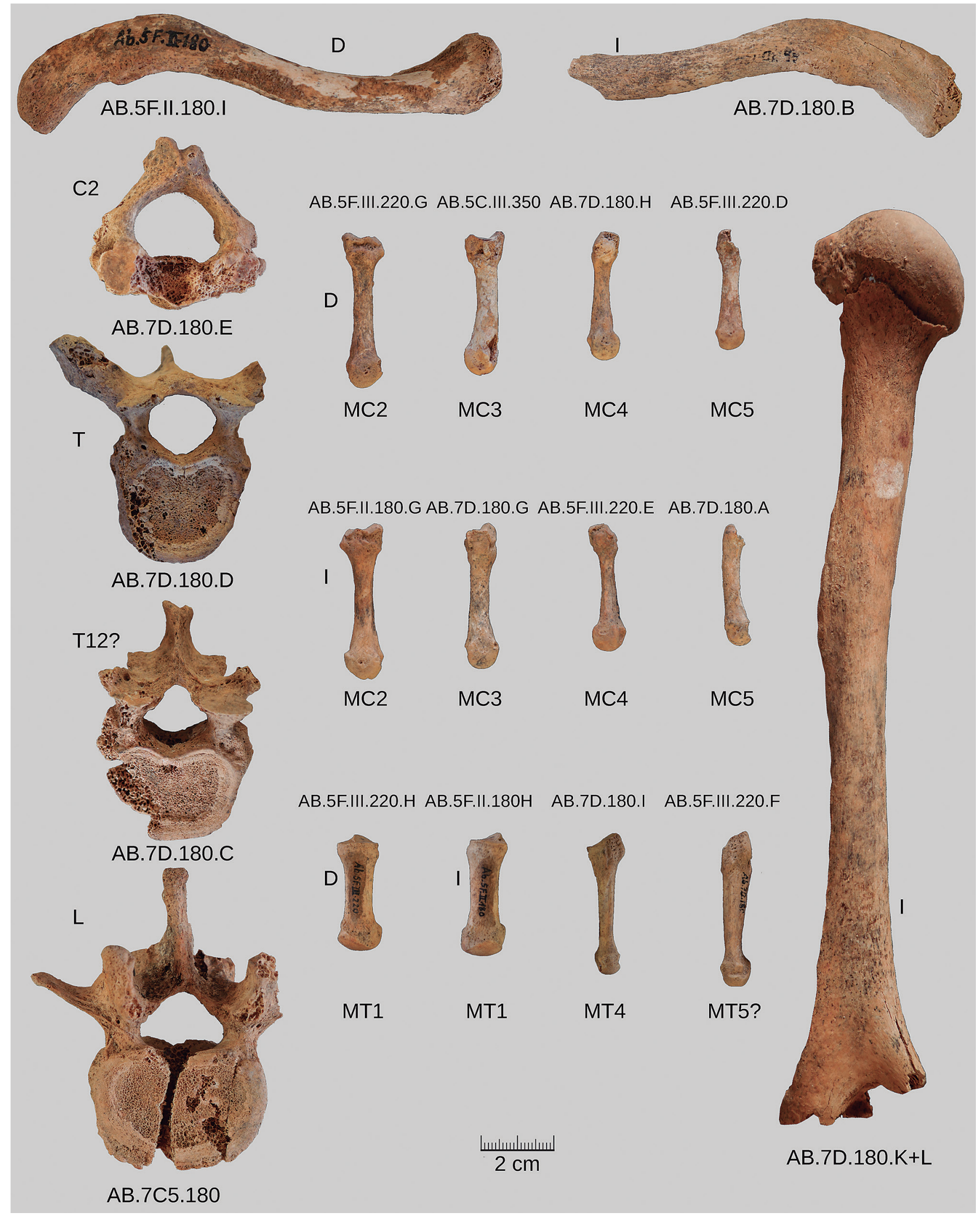

Fig.9. Selección de los restos humanos recuperados en Abittaga. $D=$ lado derecho; $I=$ lado izquierdo. $C=$ vértebra cervical; $T=$ vértebra torácica; $L=$ vértebra lumbar. $\mathrm{MC}$ = hueso metacarpiano; MT = hueso metatarsiano. En el extremo superior de la figura se muestran las dos clavículas, en la columna de la izquierda las vértebras, en la parte central los huesos metacarpianos (dos filas superiores) y metatarsianos (fila inferior), y en la parte derecha el húmero izquierdo. $/$ Selected human remains from Abittaga. $\mathrm{D}=$ right side; $\mathrm{I}=$ left side. $\mathrm{C}=$ cervical vertebra; $T$ = thoracic vertebra; $\mathrm{L}=$ lumbar vertebra. $\mathrm{MC}=$ metacarpal bones; MT = metatarsal bones. Top of the figure: the two clavicles are shown; on the left column the vertebrae; on the central part of the figure the metacarpal (the upper two rows) and metatarsal (lower row) bones; and finally, on the right side, the left humerus. 
gías, impidiendo así garantizar la integridad del depósito (Tabla S6.1). A pesar de ello, llama poderosamente la atención la inexistencia de materiales realizados claramente a torno, al menos, en el nivel más superficial de la secuencia lo que posiblemente se debe a una selección en la recogida de materiales cerámicos. No se han identificado materiales que se puedan atribuir claramente a un uso de la cavidad durante el Neolítico, aunque la indefinición morfológica y decorativa de los conjuntos cerámicos neolíticos de la región no permite apuntar rasgos característicos de estos primeros conjuntos cerámicos (Cubas, 2013). En segundo lugar, la presencia de grandes orzas y las decoraciones de barro plástico permiten apuntar una ocupación a finales del III y mediados II milenio cal BC, momento al que se adscriben estos materiales en función de las dataciones obtenidas en otros yacimientos de la región cantábrica. Por último, el pequeño cuenco cerrado documentado en el nivel III (Figura 7, nivel III) y la fusayola (Figura 8: C), generalmente relacionada con la aparición de las actividades textiles, podrían relacionarse con una ocupación posterior en torno a finales del II-mediados del I milenio cal BC. De tal manera y, a pesar de no poder individualizar estratigráficamente las distintas ocupaciones, se pueden apuntar distintas actividades en la cavidad entre el III y el I milenio cal BC, posiblemente de distinta naturaleza destacando un episodio funerario datado directamente entre el 1895-1689 cal BC (Ua64120: $3478 \pm 36$ BP. Ver S4, Tabla S4.1). Los paralelos más cercanos en Bizkaia serían dos de las dataciones directas en restos humanos de las cuevas de Arlanpe (Beta-339110: $3580 \pm 30$ BP; Beta-299200: $3510 \pm 30$ BP; Rios-Garaizar et al., 2013), el individuo inmaduro (Individuo 1) de la cercana cueva de Lumentxa (Beta493404: 3550 土 30 BP; García-Sagastibelza et al., en prensa), el individuo de Kobaederra (AA-29109: $3545 \pm$ 60 BP; Ibañez et al., 1999) y dos de las dataciones de Urratxa III (Ua-11430: $3405 \pm 70$ BP; Ua-11431: $3475 \pm$ 80 BP; Muñoz Salvatierra and Berganza, 1997).

El nivel IV ofrece muy pocos elementos que permitan hacer una evaluación ponderada del mismo, pero la ausencia de cerámica parece imposibilitar una atribución a la Prehistoria Reciente, siendo posiblemente del final del Paleolítico o al Mesolítico. Los niveles V y VI también han proporcionado escasos materiales, pero se asemejan bastante a los recuperados en el nivel VII.

El nivel VII fue asignado por J. M. Barandiarán al Magdaleniense VI y posteriormente C. González Sainz concretó su pertenencia al Magdaleniense Superior final Cantábrico (González Sainz, 1983). La datación obtenida, entre 14321 y 14051 cal BP (Beta-457783: $12240 \pm 40$ BP. Ver S4, Tabla S4.1) se encuadra perfectamente en las dataciones del Magdaleniense Superior final de la cuenca del Lea, el resultado es coincidente con los de la Unidad 2 de Atxurra, con el conjunto interno asociado al arte rupestre de Atxurra, con los de la Unidad IV de Armiña (Rios-Garaizar et al., 2020) y con los del nivel III de Santa Catalina (Berganza y Arribas, 2014a), y algo más antiguo que las dataciones obtenidas en Laminak II (Berganza y Arribas, 1994). El nivel, aunque espeso, parece corresponderse con un número pequeño de eventos de ocupación, a tenor de la aparente uniformidad del registro arqueológico, con varias series de remontajes (S6, Tabla S6.1), y por la propia articulación del espacio en torno a una estructura de hogar, tal y como queda reflejado en las memorias de J.M. Barandiarán $(1969,1971)$ y en la propia presencia de materiales quemados en este nivel. El conjunto lítico recuperado muestra algunas peculiaridades respecto al típico conjunto magdaleniense en cueva de la región. Se distinguen dos cadenas operativas, una de producción de laminillas a partir de núcleos sobre pequeños cantos o sobre lasca, destacando las producciones a partir de buriles espesos. Esta cadena operativa está bien representada en el conjunto, como evidencian la presencia de núcleos, productos de acondicionamiento, laminillas y laminillas retocadas. Esta imagen queda reforzada también por las secuencias de remontajes identificadas en el nivel, que implican algunas secuencias de talla cortas a partir de buriles nucleiformes. Por otro lado, hay otra cadena operativa, de fabricación de láminas de gran porte, que está representada sólo parcialmente en el yacimiento. Estas láminas son los soportes de parte de los útiles retocados, especialmente de las hojas retocadas total o parcialmente. Esta cadena operativa parece que se desarrolla fuera del yacimiento y que a éste se importan productos ya terminados, aunque la presencia de productos de acondicionamiento provenientes de este tipo de producciones puede estar indicando el transporte de núcleos y la producción in situ de láminas. Destaca también la escasez de útiles retocados, y especialmente la ausencia de raspadores, esto parece indicar una cierta especialización funcional del conjunto. La abundancia de buriles coincide con la abundancia de elementos de industria ósea, especialmente azagayas y arpones. Esta composición del utillaje recuerda a otros niveles, como el nivel III de Santa Catalina, en el que hay un predominio de los buriles, abundancia de laminillas de dorso y una rica industria ósea con numerosos y variados arpones (Berganza y Arribas, 2014b), o a la del Magdaleniense Superior final de Atxurra con un predominio de buriles y hojitas retocadas, aunque sin la rica industria ósea de Abittaga (Rios-Garaizar et al., 2019). La industria ósea de Abittaga es especialmente rica, varios de los objetos recuperados por J.M. Barandiarán, tanto azagayas como arpones, muestran fracturas que son compatibles con un uso como armas de caza/pesca. El análisis funcional de objetos semejantes recuperados en el Magdaleniense Superior de El Horno (Ramales de la Victoria, Cantabria), datado en el 15380-14070 cal BP (GX-27457: 12,530 $\pm 190 \mathrm{BP}$ ) ha puesto de manifiesto su uso en actividades de caza o de pesca de grandes peces (Fano et al., 2013). En el registro faunístico de Abittaga hay restos de peces en los niveles VI y VII, y respecto a la macrofauna destacan los restos de ciervo y cabra. Resulta interesante la presencia de conchas 
de gasterópodos marinos en los niveles $\mathrm{V}$ y VII, que vinculan el yacimiento con la explotación del margen costero, cuya posición para el Magdaleniense Superior ha sido estimada 4-5 km más lejos que la posición actual (Berganza y Arribas, 2014b), a unos 8 km de distancia en línea recta. La posición de Abittaga, casi 80 m por encima del cauce del Lea, en una zona en la que el río va encajado y con escasa visibilidad desde la boca de la cueva, es semejante a la de otros yacimientos del entorno como Atxurra (Figura 1). En contextos geográficamente próximos, como el valle del Asón, se ha puesto de relieve el abandono de los grandes lugares referenciales que se ocupan durante el Magdaleniense Inferior y la ocupación de cuevas cada vez más pequeñas, con ocupaciones más efímeras, y que además están situadas en puntos de escasa visibilidad, se ha interpretado como un efecto de "la disgregación de los grupos de cazadores-recolectores en unidades más pequeñas" (García Moreno, 2010: 333).

Las características del conjunto arqueológico del nivel VII parecen indicar que la cueva de Abittaga fue utilizada como campamento ocasional, probablemente un alto de caza, en el que, en torno a un hogar, se realizaron actividades de reaprovisionamiento de utillaje lítico y de reparación y sustitución de utillaje óseo. La presencia de algunas manchas de color rojo en muy mal estado junto a la zona de ocupación, y atribuidas en principio a este momento de ocupación (Garate, 2017), sugieren también el desarrollo de otras actividades, quizás de naturaleza artística-simbólica en la boca de la cueva.

La ocupación del Magdaleniense Superior de Abittaga fue probablemente realizada por los mismos grupos magdalenienses que ocuparon y decoraron algunas de las cuevas del entorno, como Santa Catalina, Lumentxa, Armiña o Atxurra (Figura 1). Todos estos yacimientos evidencian un complejo patrón de ocupación de un territorio, la cuenca de Lea, en la que la presencia humana durante el Magdaleniense Superior parece especialmente intensa, con yacimientos de diferente tipología relacionados entre sí. En otros puntos de la región cantábrica, por ejemplo, el valle del Asón o el tramo final del Deba, se reconocen al final del Magdaleniense redes de asentamientos compuestas por emplazamientos de tipologías diversas que sugieren una creciente territorialización, en línea con la idea de la atomización de los grupos de cazadores-recolectores (González Sainz y González Urquijo, 2004; García Moreno, 2010). Hay, sin embargo, otros indicadores que sugieren la existencia, en el Magdaleniense Superior, de relaciones entre grupos que se dan en marcos geográficos más amplios. Por ejemplo, en yacimientos como Abittaga, El Horno o Arenaza, se documentan porcentajes relevantes de materias primas líticas de origen lejano, 13\% de sílex de Urbasa (ca. $60 \mathrm{~km}$ ) en Abittaga (Tabla S6.1), 8.6\% de Monte Picota (ca. $50 \mathrm{~km}$ ) en El Horno, o el $21 \%$ de sílex traslúcido (ca. $50 \mathrm{~km}$ ) en el caso del nivel $\mathrm{V}$ de Arenaza (Fano et al., 2020; Rios-Garaizar y San Emeterio, 2012). Sin embar- go, en otros yacimientos más cercanos, como Atxurra, el porcentaje de sílex lejano es muy bajo (Rios-Garaizar et al., 2019). Otro ejemplo de estas amplias redes de comunicación durante el Magdaleniense Superior sería la existencia de tipos de ciertos tipos representaciones, como las cabras en visión frontal, que aparecen en yacimientos como Atxurra (Garate et al., 2020), pero que tienen una amplia distribución en la cornisa cantábrica, en los Pirineos centrales y en la Dordoña, lo que refuerza la idea de cierta unidad cultural o de fluidez en la transmisión de conceptos e ideas durante el Magdaleniense Superior (Rivero et al., 2014).

\section{CONCLUSIONES}

La revisión de la colección de Abittaga, excavada por J.M. Barandiarán, ha permitido obtener una visión global de los usos prehistóricos de la cavidad, especialmente de las ocupaciones que se dan entre el III y el I milenio cal BC, incluyendo el uso funerario para enterrar un individuo adulto; y las ocupaciones del Magdaleniense Superior, que hemos interpretado como un campamento ocasional en el que se realizaron actividades de mantenimiento del utillaje y probablemente otras actividades de carácter simbólico-ritual. Por otro lado, la excavación realizada en 2016 ha proporcionado muy poca información y no ha permitido contrastar las estratigrafías descritas por J.M Barandiarán y J.M. Apellániz. Probablemente las excavaciones del primero agotaron el potencial estratigráfico de un testigo conservado junto a la pared derecha del vestíbulo de entrada, estando las ocupaciones prehistóricas en el resto de este vestíbulo totalmente arrasadas por fenómenos vinculados con el desarrollo del karst, aunque es posible que bajo el potente cono de derrubios de la entrada aún queden preservadas evidencias de estas ocupaciones.

\section{INFORMACIÓN SUPLEMENTARIA}

http://www.aranzadi.eus/fileadmin/docs/Munibe/ maa.2020.71.06_anexo.pdf

\section{AGRADECIMIENTOS}

La intervención y el estudio de materiales antiguos en la cueva de Abittaga, fue autorizada y subvencionada por el Servicio de Patrimonio Cultural de la Diputación Foral de Bizkaia (A013/2016, 72095530YA). AGO ha recibido apoyo de FEDER/Ministerio de Ciencia e Innovación-Agencia Estatal de Investigación (proyecto PGC2018-093925-B-C33), del Grupo de Investigación IT1418-19 de Eusko Jaurlaritza-Gobierno Vasco y tiene un contrato Ramón y Cajal (RYC-2017-22558). AGS tiene un contrato predoctoral de la UPV/EHU para realizar la tesis en cotutela entre dicha universidad y la Universidad de Burdeos. Iñaki Intxaurbe (UPV/EHU) nos ha proporcionado las coordenadas de los yacimientos reflejadas en el mapa de la Figura 1. Queremos agra- 
decer al Arkeologi Museoa de Bilbao las facilidades concedidas para la consulta de materiales y de documentación anexa, especialmente a Sonia Aníbarro. Encarnación Regalado y Ander Ugarte colaboraron en la excavación de 2016.

\section{BIBLIOGRAFÍA}

Apellániz, J.M., 1973. Corpus de materiales de las culturas prehistóricas con cerámica de la población de cavernas del País Vasco meridional. Sociedad de Ciencias Aranzadi, San Sebastián. (Munibe, Sup. 1).

Arias, P., 1991. De cazadores a campesinos. La transición al neolítico en la región cantábrica. Universidad de Cantabria, Santander.

Arribas, J.L., 1994. Cueva de Lumentxa (Lekeitio): VIII campaña de excavaciones. Arkeoikuska 1993, 105-107.

Barandiarán, J.M., 1969. Excavaciones en Abittaga (Amoroto-Vizcaya). Campaña de 1965. Noticiario Arqueológico Hispánico X-XI y XII, 280-287.

Barandiarán, J.M., 1971. Excavaciones en Abittaga (Amoroto-Vizcaya). Campaña de 1966. Noticiario Arqueológico Hispánico XIII-XIV, 291-306.

Berganza, E., Arribas, J.L., 1994. El asentamiento paleolítico de Laminak II (Berriatua, Bizkaia). Kobie Paleoantropología 21, 5-7.

Berganza, E., Arribas, J.L., 2014a. La intervención arqueológica en el yacimiento de la cueva de Santa Catalina. In: Berganza, E., Arribas, J.L. (coords.), La Cueva de Santa Catalina (Lekeitio, Bizkaia): La intervención arqueológica. Restos vegetales, animales y humanos. Diputación Foral de Bizkaia, Bilbao. Kobie Serie BAI 4, 7-24.

Berganza, E., Arribas, J.L., 2014b. El entorno físico de las ocupaciones de Santa Catalina. In: Berganza, E., Arribas, J.L. (coords.), La Cueva de Santa Catalina (Lekeitio, Bizkaia): La intervención arqueológica. Restos vegetales, animales y humanos, 367-378. Diputación Foral de Bizkaia, Bilbao. Kobie Serie BAI 4

Castaños, P., 1986. Los macromamíferos del Pleistoceno y Holoceno de Vizcaya. Tesis Doctoral, Universidad del País Vasco.

Cubas, M., 2013. La aparición de la tecnología cerámica en la región cantábrica. Archaeopress, Oxford. BAR International Series 2566.

Fano, M.A., Chauvin, A., Clemente-Conte, I., Tarriño, A., Teira, L.C., 2020. Magdalenian knappers in the Asón Valley: Level 2 at El Horno Cave (Ramales de la Victoria, Cantabria, Spain). Journal of Archaeological Science: Reports 30. https://doi.org/10.1016/j.jasrep.2020.102230.

Fano, M.A., Clemente, I., Rivero, O., 2013. Apuntes en torno al uso de los arpones magdalenienses: primeras observaciones microscópicas a partir de los materiales de El Horno (Ramales de la Victoria, Cantabria). Trabajos de Prehistoria 70, 332-345.

Fernández Eraso, J., 1985. Las culturas del Tardiglaciar en Vizcaya. Universidad del País Vasco, Vitoria.

Fernández Ibáñez, C., 1986. El grabado esquemático sobre canto rodado de la caverna de Abittaga (Vizcaya). Pirineos $128,141-144$.

Garate, D., 2012. Neandertales y Cromañones. Los primeros pobladores de Bizkaia. Guías del Arkeologi Museoa, 2. Diputación Foral de Bizkaia y Arkeologi Museoa, Bilbao.
Garate, D., 2017. Redescubriendo el arte parietal paleolítico (Kobie Anejo, 16). Diputación Foral de Bizkaia, Bilbao.

Garate, D., Rios-Garaizar, J., Ruiz, A., 2013. El arte parietal paleolítico de la cueva de Lumentxa (Lekeitio, Bizkaia). Kobie Paleoantropología 32, 5-28.

Garate, D., Líbano, I., Vega, S., 2015. Cueva Abittaga. I Campaña. Estudio de arte rupestre. Arkeoikuska 2015, 174-175.

Garate, D., González, C., Intxaurbe, I., 2016-2017. Arte parietal paleolítico en la cueva de Ondaro (Nabarniz, Bizkaia). Kobie Paleoantropología 35, 37-48.

Garate, D., Rivero, O., Rios-Garaizar, J., Arriolabengoa, M., Alcaide, M.A., Ruiz, J., Intxaurbe, I., Salazar, S., Libano, I., 2020. The cave of Atxurra: A new major Magdalenian rock art sanctuary in Northern Spain. Journal of Archaeological Science: Reports 29. https://doi.org/10.1016/j.jasrep.2019.102120.

García Moreno, A., 2010. Patrones de asentamiento y ocupación del territorio en el Cantábrico oriental al final del Pleistoceno una aproximación mediante SIG. Tesis Doctoral, Universidad de Cantabria, Santander. Disponible en: https://www. educacion.es/teseo/mostrarRef.do?ref=854409.

García-Sagastibelza, A., Arribas Pastor, J.L., López-Onaindia, D., Pomeroy, E., Rodríguez-Hidalgo, A., Castex, D., Couture-Veschambre, C., Gómez-Olivencia, A., en prensa. The human remains from the Lumentxa cave (Lekeitio, Biscay, Northern Iberian Peninsula): Paleobiology, taphonomy and chronology. Quaternary International. https://doi.org/10.1016/j. quaint.2020.06.043.

García-Sagastibelza, A., López-Onaindia, D., Lambacher, N., Pomeroy, E., Cubas, M., Subirà, M.E., Castex, D., Couture-Veschambre, C., Gómez-Olivencia, A., en prensa. The funerary use of caves during the Holocene in the Atlantic Western Pyrenees: new information from Atxuri-I and Txotxinkoba caves (Biscay, Northern Iberian Peninsula). Quaternary International. https://doi.org/10.1016/j.quaint.2020.09.029.

González Sainz, C., 1983. Las industrias del Magdaleniense Superior-Final de la Cueva de Abittaga (Amoroto, Vizcaya). Kobie Paleoantropología 13, 59-71.

González Sainz, C., González Urquijo, J.E., 2004. El Magdaleniense reciente en la Región Cantábrica. In: Fano, M.A. (Coord.), Las sociedades del Paleolítico en la Región Cantábrica, 275308. Diputación Foral de Bizkaia, Bilbao. Kobie Anejo, 8.

González Sainz, C., López Quintana, J.C., 2017a. Cueva de Armintxe. Estudio del arte parietal. Arkeoikuska 2016, 290-294.

González Sainz, C., López Quintana, J.C., 2017b. Cueva de Goikolau. Estudio del arte parietal, I Campaña. Arkeoikuska 2016, 245-250.

Ibáñez, J.J., Zapata, L., González Urquijo, J., 1999. Cueva de Kobaederra (Kortezubi): V Campaña de excavación. Arkeoikuska 1999, 70-72.

Larrea Robles, M., 2017. La industria ósea Magdaleniense de las cuevas de Abittaga (Amoroto-Bizkaia) y Lumentxa (Lekeitio-Bizkaia). Trabajo Fin de Master. UNED, Madrid.

Le Brun-Ricalens, F., Brou, L., 2003. Burins carénés-nucléus à lamelles: identification d'une chaîne opératoire particulière à Thèmes (Yonne) et implications. Bulletin de la Société Préhistorique Française 100, 67-83.

Llanos, A., 1966. Resumen Tipológico del Arte Esquemático en el País Vasco-Navarro. Estudios de Arqueología Alavesa 1, 149-158. 
Meadows, L., A., M., Jantz, R. L. 1992. Estimation of Stature from Metacarpal Lengths. Journal of Forensic Sciences 37(1), 147-154.

Muñoz, F.J., San Nicolás, M.P., 2010. La cultura material como fuente esencial de conocimiento en Arqueología. UNED, Madrid.

Muñoz Salvatierra, M., Berganza, E., 1997. La cueva de Urratxa III (Orozko, Bizkaia). Excavación, cronología y análisis de las industrias lítica y ósea. El canto pintado. En: Muñoz Salvatierra, M., Berganza, E. (Eds.), El yacimiento de la cueva de Urratxa III (Orozko, Bizkaia), 9-71. Universidad de Deusto, Bilbao.

Pablos, A., Gómez-Olivencia, A., García-Pérez, A., Martínez, I., Lorenzo, C., Arsuaga, J.L., 2013. From toe to head: Use of robust regression methods in stature estimation based on foot remains. Forensic Science International 226, 299e1-299e7.

Pétillon, J.M., 2000. Les pointes à base forchue magdaléniennes: aproche fonctionnelle. Préhistoire Anthropologie Méditerranéennes 9, 29-55.

Pétillon, J.M., Cattelain, P., 2004. Nouvel examen de I'armature composite magdalénienne du Tuc d'Audoubert (Montesquieu-Avanès, Ariège). Bulletin de la Société Préhistorique Française 101, 45-53.

Rios-Garaizar, J., Garate Maidagán, D., Gómez-Olivencia, A., 2013. Ocupaciones humanas prehistóricas en el yacimiento de la cueva de Arlanpe (Lemoa, Bizkaia). En : Rios-Garaizar, J., Garate Maidagán, D., Gómez-Olivencia, A. (Eds.), La cueva deArlanpe (Lemoa): Ocupaciones humanas desde el Paleolítico Medio Antiguo hasta la Prehistoria Reciente, 277-294. Bizkaiko Foru Aldundia-Diputación Foral de Bizkaia, Bilbao. Kobie, Serie BAI, 3.
Rios-Garaizar, J., San Emeterio Gómez, A., 2012. Avance del estudio de la industria lítica del yacimiento de Arenaza I (Galdames, Bizkaia). Informe. Arkeologi Museoa, Bilbao.

Rios-Garaizar, J. San Emeterio, A., Larrea Robles, M., Marín-Arroyo, A.B., Agudo Pérez, L., Cubas Morera, M., Garate Maidagan, D., 2019. La secuencia prehistórica de la cueva de Atxurra (Berriatua, Bizkaia): evaluación de las excavaciones de J.M. Barandiarán Ayerbe (1934-1935). Munibe Antropologia-Arkeologia 70, 21-34.

Rios-Garaizar, J., San Emeterio, A., Arriolabengoa, M., Aranbarri, J., Rofes, J., Marín-Arroyo, A.B., Rivero, O., Intxaurbe, I., Arranz-Otaegui, A., Salazar, S., Medina-Alcaide, M.Á., Garate, D., 2020. Sporadic occupation in Armiña cave during the Upper Magdalenian: What for? Journal of Archaeological Science: Reports 30, 102271. https://doi.org/10.1016/J.JASREP.2020.102271.

Rivero, O., Fano, M., Garate, D., 2014. Relationships between recent Magdalenian societies in Cantabrian Spain, through the technical and formal analysis of frontal representations of Ibex. In: Otte, M., Le Brun F. (Coords.), Modes de contacts et de déplacements au Paléolithique eurasiatique, 589-601. ERAUL 140.

Scheuer, L., Black, S., 2000. Developmental Juvenile Osteology. Elsevier Academic Press, Gran Bretaña.

Urrutia, A.M, Urrutia, S., ADES, 2005. Karlisten arma gordelekua Abittagako koban (Amoroto-Bizkaia): aurkikuntza arkeologiko batek historia garaikideko gertakizun bitxiak ateratzen ditu argitara. Illunzar 5, 99-114 
